\title{
Sex hormone binding globulin gene polymorphisms and metabolic syndrome in postmenopausal Turkish women
}

\author{
Murat Sunbul ${ }^{1}$, Fatih Eren ${ }^{2}$, Cevdet Nacar $^{3}$, Mehmet Agirbasli $^{1}$ \\ ${ }^{1}$ Department of Cardiology, Marmara University Medical School, Haydarpaşa, Istanbul, Turkey \\ ${ }^{2}$ Molecular Biology Laboratory Gastroenterology Institute, \\ Marmara University Medical School, Basibüyük, Istanbul, Turkey \\ ${ }^{3}$ Department of Biophysics, Marmara University Medical School, Haydarpaşa, Istanbul, Turkey
}

\begin{abstract}
Background: Insulin resistance is associated with obesity, glucose intolerance or diabetes, hypertension, dyslipidemia, and cardiovascular disease. Constellation of these risk factors is called metabolic syndrome (MetS). MetS is common among postmenopausal women. Low sex hormone binding globulin (SHBG) levels associate with an increased risk of MetS in postmenopausal women. Variations in SHBG gene associate with low levels of circulating SHBG levels. We aim to study the association between SHBG gene polymorphisms - rs1799941 $(\mathrm{A} / \mathrm{G})$ and rs6257 (T/C) — with MetS among postmenopausal women.

Methods: The study population consisted of 182 postmenopausal women with MetS and 119 control subjects. We analyzed the allele frequencies of SHBG gene polymorphisms in relation to the risk components of MetS.

Results: MetS patients displayed significantly lower SHBG levels compared to the lean control subjects $(p=0.036)$. rs1799941 A allele was associated with high SHBG levels $(p=0.031)$, low blood pressure, body mass index and waist circumference. The number of 'high risk' alleles ( $G$ allele of the rs1799941 and T allele of $r$ 6257) correlated positively with waist circumference ( $r=0.203, p=0.006)$ and negatively with SHBG levels $(r=-0.291, p=0.024)$.

Conclusions: $S H B G$ gene polymorphisms associate with $S H B G$ levels and MetS risk components among postmenopausal women. Hence, A allele (rs1799941) may have a protective effect for MetS through its association with high SHBG levels among postmenopausal women. (Cardiol J 2013; 20, 3: 287-293)
\end{abstract}

Key words: SHBG gene polymorphisms, metabolic syndrome, postmenopausal

\section{Introduction}

Current smoking, dyslipidemia, elevated blood pressure, overweight and obesity remain as major causes of morbidity and mortality from cardiovascular disease, thrombosis, stroke, kidney disease, and diabetes mellitus throughout the world [1,2].
Insulin resistance is associated with obesity, glucose intolerance or diabetes, hypertension, dyslipidemia, and cardiovascular disease. Constellation of these risk factors is called metabolic syndrome (MetS) [1-3]. Sex hormones are important in the modulation of insulin resistance and MetS [4]. Decline in sex hormone levels may contribute to

Address for correspondence: Mehmet Agirbasli, Prof. MD, FACC, Göztepe Mahallesi, Yeşilbahar Sokak, No: 68/14 Kadıköy, İstanbul, Turkey, tel: 902165327468840, fax: 902122250139, e-mail: magirbasli@gmail.com 
the increasing cardiovascular risk and MetS occurring in postmenopausal women. Low levels of sex hormone binding globulin (SHBG) indicate a higher risk of MetS and components in postmenopausal women [4-6]. Similar observations were made in men [7] and postmenopausal women [8]. Thus, it is likely that the relationship of sex hormones and MetS is through low SHBG levels. For instance, in a cohort of elderly Turkish men and women; type 2 diabetes mellitus, elevated apolipoprotein $\mathrm{B}$ and triglyceride, or reduced high density lipoprotein cholesterol (HDL-C) levels were all associated with low SHBG levels [4, 5]. Hence, low SHBG level is a valuable biomarker of increased cardiometabolic risk in postmenopausal women.

Genetic variations in the SHBG gene affect the circulating sex hormone levels [9-11]. Therefore, genetic factors that lower SHBG levels may potentially result in type 2 diabetes mellitus, high blood pressure, and obesity [9]. In fact, previous studies show that SHBG gene polymorphisms associate with insulin resistance [6]. G allele of the rs1799941 and T allele of rs6257 polymorphisms of SHBG gene result in low SHBG levels $[10,11]$.

Metabolic syndrome is extremely common (40\%) among Turkish postmenopausal women [12]. We aim to examine the association between the SHBG gene polymorphisms (rs1799941 A/G and rs6257 T/C) and MetS risk components among postmenopausal Turkish women.

\section{Methods}

\section{Study population}

The study population consists of postmenopausal women (age $>50$ ). Patients were selected from consecutive subjects who applied to outpatient clinics between June 2009 and June 2010. MetS is defined according to the National Cholesterol Education Program (NCEP), Adult Treatment Panel III criteria [13]. The NCEP definition is based on the presence of 3 or more of the 5 risk criteria: waist circumference $(>88 \mathrm{~cm})$, elevated triglycerides $(>150 \mathrm{mg} / \mathrm{dL})$, reduced HDL-C $(<50 \mathrm{mg} / \mathrm{dL})$, elevated blood pressure $(>130 / 85 \mathrm{~mm} \mathrm{Hg}$ or history of hypertension) and elevated fasting glucose ( $>110 \mathrm{mg} / \mathrm{dL}$ or history of adult onset diabetes mellitus).

Postmenopausal state was confirmed by history and clinical evaluation. We selected women older than 50 years who had not menstruated for at least 1 year and/or had not taken hormone replacement therapy for at least 3 months prior to the sampling. Subjects with concomitant malignancy, end stage renal disease, vasculitis and other chronic medical conditions were excluded from the study (nearly $20 \%$ ). Lean postmenopausal women (body mass index $[\mathrm{BMI}]<25 \mathrm{~kg} / \mathrm{m}^{2}$ ) without history of diabetes mellitus, hypertension and hyperlipidemia were selected as the control group.

The study was approved by the local Ethics Committee of the Marmara University Medical School. Written consent was obtained from all the subjects.

\section{Measurements}

Blood pressure and anthropometric measurements were collected by standardized methods. The weight of subjects wearing minimal clothing was measured to the nearest $0.1 \mathrm{~kg}$ with a portable electronic scale. Each time it was moved, the scale was recalibrated and standardized. Height was measured with fiberglass tape. BMI was calculated as weight $[\mathrm{kg}] / \mathrm{height}^{2}\left[\mathrm{~m}^{2}\right]$. Body circumferences were measured with subjects in the standing position. Waist (just above the iliac crest) circumference was measured to the nearest $0.1 \mathrm{~cm}$. Blood pressure was measured 3 times by an automatic blood pressure monitor $\left(\mathrm{Omron}^{\circledR}\right)$ while the subjects were seated, and the last 2 measurements were averaged for analysis. Medium and large-sized cuff were used for arm circumferences of 22-32 and $>32 \mathrm{~cm}$, respectively.

\section{Laboratory procedures}

Fasting blood samples were collected at 9.00 a.m. and serum levels of fasting blood glucose, HDL-C, triglyceride and SHBG were measured at the University laboratories. Two milliliters of venous blood were collected from the study subjects into the tubes containing ethylenediamine tetraacetic acid, then stored at $+4^{\circ} \mathrm{C}$. Genomic DNA was isolated from peripheral blood leukocytes using a High Pure PCR Template Preparation Kit (Roche Diagnostics, Mannheim, Germany) within 1 week. Genotyping of the rs6257 and rs1799941 polymorphisms was performed by real time PCR using fluorescence melting curve detection analysis by means of the Light Cycler 1.5 System (Roche Diagnostics, Mannheim, Germany). Primers and hybridization probes were designed using GenBank reference sequence NG_011981.

Hybridization probes are indicated below: for rs6257 gene polymorphism, sensor hybridization probe was 5'-CAGCTTTGTTT-GCTTTCTCTTTCTGA-fluorescein-3'and anchor hybridization probe was 5'-LCRed640-AGAGTGCCCACGACCCTCCGG-phosphate-3'. 
Table 1. Anthropometric and laboratory characteristics of the subjects with metabolic syndrome compared with the control group.

\begin{tabular}{lccc} 
& $\begin{array}{c}\text { Metabolic syndrome } \\
\text { (n = 182) }\end{array}$ & $\begin{array}{c}\text { Control group } \\
\text { (n = 119) }\end{array}$ & P \\
\hline Age [years] & $60.4 \pm 9.8$ & $61.0 \pm 11.0$ & 0.606 \\
Height [cm] & $158(5 \%)$ & $160(6 \%)$ & $<0.001$ \\
Weight $[\mathrm{kg}]$ & $82.91 \pm 13.4$ & $61.95 \pm 6.7$ & $<0.001$ \\
Body mass index $\left[\mathrm{kg} / \mathrm{m}^{2}\right]$ & $32(6.8 \%)$ & $24.15(2.2 \%)$ & $<0.001$ \\
Waist circumference $[\mathrm{cm}]$ & $98(12 \%)$ & $84.5(3 \%)$ & $<0.001$ \\
Systolic blood pressure $[\mathrm{mm} \mathrm{Hg]}$ & $140(20 \%)$ & $123.5(20 \%)$ & $<0.001$ \\
Dystolic blood pressure $[\mathrm{mm} \mathrm{Hg]}$ & $80.5(10 \%)$ & $70(15 \%)$ & $<0.001$ \\
Glucose $[\mathrm{mg} / \mathrm{dL}]$ & $111(26 \%)$ & $99.5(17 \%)$ & $<0.001$ \\
HDL-C [mg/dL] & $50.3 \pm 13.7$ & $58.34 \pm 16.6$ & $<0.001$ \\
Triglyceride $[\mathrm{mg} / \mathrm{dL}]$ & $143.5(94 \%)$ & $106(61 \%)$ & $<0.001$ \\
SHBG levels $[\mathrm{nmol} / \mathrm{L}]$ & $30.5(22.8 \%)$ & $38.45(29.4 \%)$ & 0.036 \\
\hline
\end{tabular}

HDL-C - high density lipoprotein cholestrol; SHBG — sex hormone binding globulin

For rs 1799941 gene polymorphism, sensor hybridization probe was 5'-CCCACACACAAGGCTGCC-fluorescein-3' and anchor hybridization probe was 5'-LC640-GCCTCTACACATTCTCCCAAGAGTT-GTCTGA-phosphate-3'.

The PCR run comprised 45 cycles of denaturation $\left(95^{\circ} \mathrm{C}, 5 \mathrm{~s}\right)$, annealing $\left(57^{\circ} \mathrm{C}, 20 \mathrm{~s}\right)$ and extension $\left(72^{\circ} \mathrm{C}, 20 \mathrm{~s}\right)$ which followed an incubation period of $10 \mathrm{~min}$ to activate the FastStart Taq DNA Polymerase of the reaction mix (Light Cycler FastStart DNA Master Hybridization Probes, Roche Diagnostics, Mannheim, Germany). After amplification, a melting curve was generated by holding the reaction time at $40^{\circ} \mathrm{C}$ for $30 \mathrm{~s}$ and then heating slowly to $85^{\circ} \mathrm{C}$ with a ramp rate of $0.1^{\circ} \mathrm{C} / \mathrm{s}$.

\section{Statistical analysis}

Power was calculated with a computer based program for genetic epidemiology studies (http:// //hydra.usc.edu/gxe), for a previously reported $28 \%$ difference in SHBG levels among the genotype groups [10], $80 \%$ power and alpha 1 error of 0.05 ; sample size was calculated as 180 . Descriptive parameters were displayed as means \pm standard deviation for variables with normal distribution and in percentages (\%) for categorical variables. Median and interquartile range (IQR) levels were displayed for variables with skewed distribution. Student's t test was used to analyze the differences in means for variables with normal distribution. Nonparametric test (Mann-Whitney) was used to compare the groups for variables with skewed distribution (i.e. BMI, waist circumference, systolic and diastolic blood pressure, glucose, triglyceride, SHBG levels). $\chi^{2}$ test was used to compare categorical variables between the groups. Nonparametric Spearman test was used to assess the correlation between the number of alleles G (rs1799941) and T (rs6257), SHBG levels and the waist circumference. A p value of less than 0.05 was accepted as statistically significant. Statistical analysis was performed using SPSS for Windows 16.0 (Statistical Package for the Social Sciences Inc. Chicago, USA).

\section{Results}

Study population consisted of postmenopausal women with MetS $(n=182)$. Lean postmenopausal women $(\mathrm{n}=119)$ without history of diabetes mellitus, hypertension and hyperlipidemia were selected as the control group (mean age $60 \pm 10$ vs. $61 \pm 11, p=0.606$ ). Baseline characteristics of the study population are displayed in Table 1 . MetS subjects had significantly lower SHBG and HDL-C levels and higher BMI, waist circumference, blood pressure, glucose and triglyceride levels compared to the control group (Table 1).

\section{SHBG gene polymorphisms}

The minor allelic frequencies for rs6257 (C) and rs1799941 (A) gene polymorphisms were $19.1 \%$ and $16.6 \%$, respectively. The genotype distributions were in accordance with the Hardy-Weinberg equilibrium $(\mathrm{p}=0.8$ for $\mathrm{rs} 6257$ and $\mathrm{p}=0.6$ for $\mathrm{rs} 1799941)$. Genotype distributions were similar between the study and the control groups $(\mathrm{p}=0.424$ [rs 1799941] and $\mathrm{p}=0.742$ 


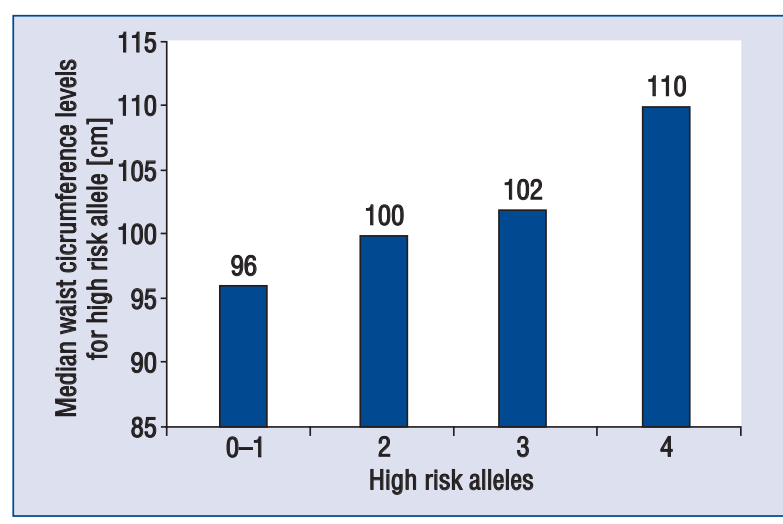

Figure 1. The total number of high risk alleles (G allele of the rs1799941 and T allele of rs6257) and waist circumference in subjects with metabolic syndrome. Median waist circumference is displayed for subjects with 4, 3, 2 and $\leq 1$ high risk alleles.

[rs 6257]). TT, CT and CC genotype distributions of rs6257 polymorphism were $65 \%, 30 \%, 5 \%$ (MetS group) and 68\%, 29\%, 3\% (control group), respectively $(\mathrm{p}=0.742)$. GG, GA and AA genotype distributions of rs1799941 polymorphism were
$66 \%, 32 \%, 2 \%$ (MetS group) and 72\%, 25\%, 3\% (control group), respectively ( $\mathrm{p}=0.424)$.

\section{SHBG gene polymorphisms}

and MetS risk criteria

The total number of high risk alleles ( $G$ allele of the rs1799941 and T allele of rs6257) correlated positively with waist circumference $(\mathrm{r}=0.203$, $\mathrm{p}=0.006)$ and negatively with SHBG levels $(r=-0.291, p=0.024)$ (Fig. 1$)$. Women with 4 high risk alleles (GG [rs1799941] and TT [rs6257] genotype) displayed the highest waist circumference (110 [17] $\mathrm{cm}$ ), while subjects carrying $\leq 1$ high risk alleles had elevated SHBG levels 45 [33] nmol/L (Fig. 1).

GG genotype of the rs1799941 was associated with low SHBG levels (Table 2): polymorphic subjects (AA or GA) had significantly higher SHBG levels compared to the wild type (GG); 44 (36) vs. 29 (17), $\mathrm{p}=0.031$ and 56 (45) vs. 34 (20), $\mathrm{p}=0.005$ for the study and the control groups respectively (Table 2, Fig. 2). A allele of rs 1799941 (A/G) polymorphism appeared to have protective effects and was associated with lower blood pressure, BMI and waist circumference (Table 2, Fig. 3).

Table 2. Anthropometric and laboratory characteristics for sex hormone binding globulin genotype groups (rs 6257 and rs 1799941).

\begin{tabular}{|c|c|c|c|c|c|c|}
\hline \multirow[b]{2}{*}{ Metabolic syndrome subjects } & \multicolumn{3}{|c|}{ rs6257 (T/C) } & \multicolumn{3}{|c|}{ rs1799941 (A/G) } \\
\hline & $\begin{array}{c}\text { TT } \\
(\mathrm{n}=118)\end{array}$ & $\begin{array}{l}\mathrm{TC}+\mathrm{CC} \\
(\mathrm{n}=64)\end{array}$ & $\mathbf{P}$ & $\begin{array}{c}\text { GG } \\
(n=120)\end{array}$ & $\begin{array}{l}\text { GA+AA } \\
(n=62)\end{array}$ & $\mathbf{P}$ \\
\hline SHBG levels [nmol/L] & $36(25 \%)$ & $28(11 \%)$ & 0.146 & $29(17 \%)$ & $44(36 \%)$ & 0.031 \\
\hline $\mathrm{SBP}[\mathrm{mm} \mathrm{Hg}]$ & $145(19 \%)$ & $144(15 \%)$ & 0.364 & $145(18 \%)$ & $142(15 \%)$ & 0.012 \\
\hline $\mathrm{DBP}[\mathrm{mm} \mathrm{Hg}]$ & $85(8 \%)$ & $83(12 \%)$ & 0.527 & $85(11 \%)$ & $80(11 \%)$ & 0.040 \\
\hline $\mathrm{BMI}\left[\mathrm{kg} / \mathrm{m}^{2}\right]$ & $32(7 \%)$ & $33(8 \%)$ & 0.329 & $33(7 \%)$ & $31(8 \%)$ & 0.029 \\
\hline Waist circumference [cm] & $98(14 \%)$ & $102(19 \%)$ & 0.196 & $102(17 \%)$ & $96(14 \%)$ & 0.003 \\
\hline Glucose levels [mg/dL] & $110(36 \%)$ & $111(28 \%)$ & 0.657 & $108(38 \%)$ & $113(31 \%)$ & 0.669 \\
\hline HDL-C levels [mg/dL] & $51 \pm 14$ & $49 \pm 14$ & 0.260 & $49 \pm 13$ & $52 \pm 16$ & 0.230 \\
\hline Triglyceride levels [mg/dL] & $152(89 \%)$ & $140(84 \%)$ & 0.399 & $151(87 \%)$ & $132(94 \%)$ & 0.267 \\
\hline Control subjects & $\begin{array}{c}\text { TT } \\
(\mathrm{n}=81)\end{array}$ & $\begin{array}{c}\mathrm{TC}+\mathrm{CC} \\
(\mathrm{n}=38)\end{array}$ & $\mathbf{P}$ & $\begin{array}{c}\text { GG } \\
(n=86)\end{array}$ & $\begin{array}{l}\mathrm{GA}+\mathrm{AA} \\
(\mathrm{n}=33)\end{array}$ & $\mathbf{P}$ \\
\hline SHBG levels [nmol/L] & $37(29 \%)$ & $38(29 \%)$ & 0.819 & $34(20 \%)$ & $56(45 \%)$ & 0.005 \\
\hline $\mathrm{SBP}[\mathrm{mm} \mathrm{Hg}]$ & $125(20 \%)$ & $125(26 \%)$ & 0.544 & $125(20 \%)$ & $125(17 \%)$ & 0.592 \\
\hline $\mathrm{DBP}[\mathrm{mm} \mathrm{Hg}]$ & $70(15 \%)$ & $70(13 \%)$ & 0.982 & $70(15 \%)$ & $70(13 \%)$ & 0.883 \\
\hline $\mathrm{BMI}\left[\mathrm{kg} / \mathrm{m}^{2}\right]$ & $25(2 \%)$ & $24(3 \%)$ & 0.196 & $25(2 \%)$ & $24(3 \%)$ & 0.656 \\
\hline Waist circumference [cm] & $85(4 \%)$ & $85(3 \%)$ & 0.441 & $85(4 \%)$ & $84(4 \%)$ & 0.348 \\
\hline Glucose levels [mg/dL] & $98(16 \%)$ & $101(16 \%)$ & 0.356 & $98(15 \%)$ & $102(17 \%)$ & 0.682 \\
\hline HDL-C levels [mg/dL] & $58 \pm 15$ & $58 \pm 20$ & 0.992 & $58 \pm 16$ & $58 \pm 18$ & 0.938 \\
\hline Triglyceride levels [mg/dL] & $106(58 \%)$ & $105(62 \%)$ & 0.758 & $104(54 \%)$ & $112(74 \%)$ & 0.531 \\
\hline
\end{tabular}

SHBG — sex hormone binding globulin; BMI — body mass index; SBP — systolic blood pressure; DBP — diastolic blood pressure; HDL-C - high density lipoprotein cholestrol 


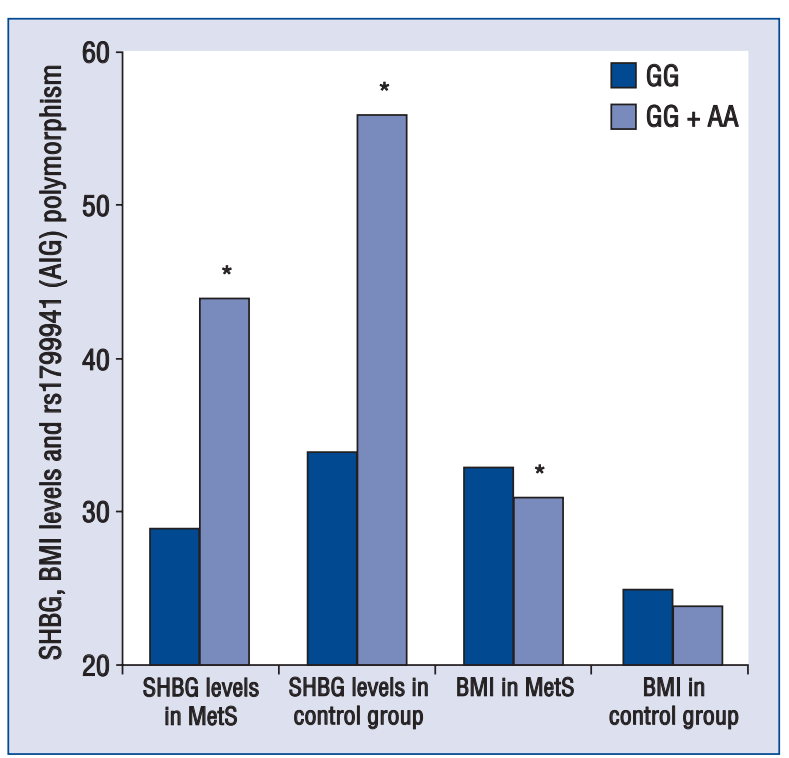

Figure 2. Sex hormone binding globulin (SHBG) and body mass index levels for rs1799941 (A/G) genotype groups; MetS — metabolic syndrome group; BMI — body mass index; ${ }^{*} p<0.05$.

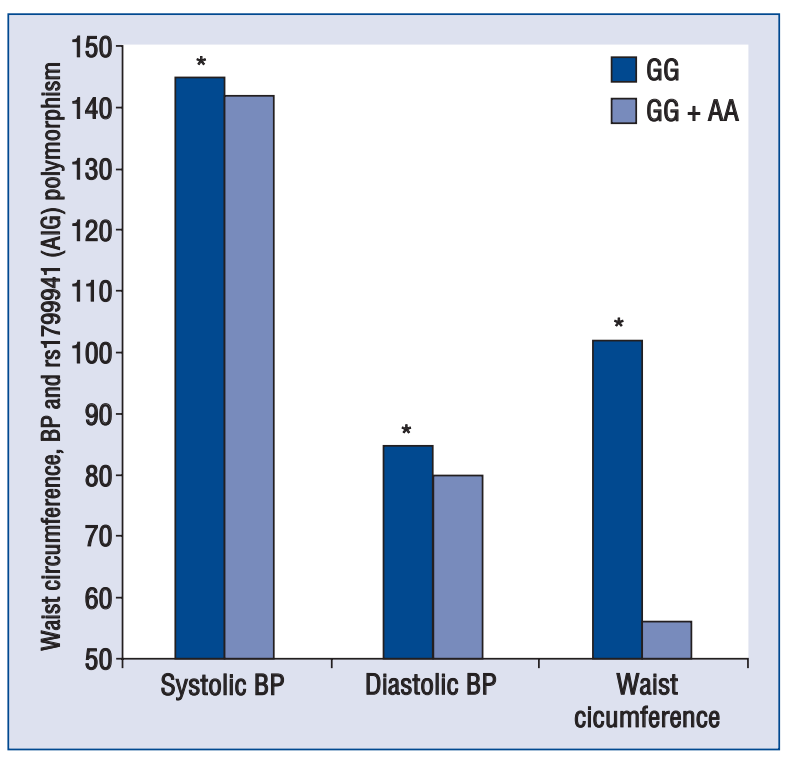

Figure 3. Blood pressure (BP) and waist circumference for rs1799941 (A/G) genotype groups; ${ }^{*} p<0.05$.

\section{Discussion}

Most common complex traits (such as MetS) are caused by the non-linear interactions of numerous genetic and environmental risk factors. The Turkish Adult Risk Factor Study reports that cardiovascular risk factors are highly prevalent in Turkish adults [14]. Epidemological studies display that MetS is extremely common (40\%) among Turkish postmenopausal women [12]. Low SHBG level is an established biomarker of insulin resistance and hyperinsulinemia [15]. Postmenopausal women with high SHBG levels have reduced risk of atherosclerosis and insulin resistance [16-18]. Genetic factors that can contribute to the diminished circulating SHBG levels are important in the onset of insulin resistance and MetS. San Antonio Family Heart Study displayed siginificant heritability for serum SHBG levels [19]. The rs6257 and rs6259 SHBG polymorphisms were consistently associated with the circulating plasma levels of SHBG [19-22].

We studied SHBG gene polymorphisms in relation to MetS risk criteria in Turkish postmenopausal women. We observed that A allele of rs1799941 polymorphism was associated with elevated SHBG levels and reduced blood pressure, and waist circumference. On the other hand, postmenopausal women carrying more than 2 high risk alleles at the 2 loci ( $G$ allele of the rs 1799941 and $\mathrm{T}$ allele of rs6257) displayed lower SHBG levels and an increased waist circumference. Therefore, polymorphic subjects (AG or AA) may be protected from MetS compared to the wild GG genotype. The study was cross sectional and comes with several limitations. Ethnic differences exist in the criteria and prevalence of MetS. Obviously, larger prospective studies are needed to confirm our observations.

Genetic and environmental risk factors are important in the onset of MetS. We studied single locus and combined effects of the 2 loci on MetS risk criteria. Unlike Mendelian diseases that are associated with a single gene, MetS is likely to be caused by the non-linear interaction of numerous genetic and environmental risk factors. Therefore, a multilocus approach is neccessary to study gene-gene and gene-environmental risk interractions. Although rs1799941 is a synonymous polymorphism in intron 1 , it is likely to be inherited with other loci that can alter SHBG levels. Similarly, rs1799941 and rs6257 polymorphisms may have synergistic effects in determining MetS risk among postmenopausal women.

The association between rs1799941 genotype and blood pressure or waist circumference was not observed in the control group. Our findings support the hypothesis that variations in the SHBG gene can cause genetic susceptibility to MetS which can be epigenetically modified by environmental risk factors (i.e. high calorie intake or lack of physical activity). 
The minor allele frequency of rs1799941 was lower among Turkish postmenopausal women compared to Spanish postmenopausal women (0.16 vs. 0.27) [23]. Minor allele frequencies in European and Sub-Saharan African population were reported as 0.22 and 0.031 , respectively. In Asian population, minor allel frequency was lower than 0.01 (http://www.ncbi.nlm.nih.gov/projects/SNP/ /snp_ref.cgi? rs $=1799941)$. The lower frequency of A allele (rs1799941) can potentially contribute to the MetS endemic among Turkish postmenopausal women.

Prior observations from different populations support the same hypothesis. SHBG gene polymorphisms were predictive of type 2 diabetes mellitus risk in the Physicians Health Study [6]. In a different study from Northern Spain, rs1799941 (A/G) and rs6257 (T/C) polymorphisms displayed stronger associations with serum SHBG levels than the rs6259 (A/G) polymorphism [23]. Post menopausal women with the AA genotype (rs1799941) showed 39\% higher SHBG levels than GG genotype [23]. In the EPIC-Norfolk study, SHBG serum levels were $28 \%$ higher with the AA vs. the GG genotype (rs1799941) [10]. In a different study among Swedish men, AA genotype was again associated with higher SHBG levels [11].

\section{Conclusions}

In conclusion, A allele of SHBG gene rs1799941 (A/G) polymorphism associates with higher serum SHBG levels and lower BMI, waist circumference and blood pressure in Turkish postnenopausal women. Prospective studies are needed to assess the cardiometabolic risk among SHBG genotype groups. Future studies should focus on the identification of genetic variants that can predispose postmenopausal women to MetS. Larger studies and novel bioinformatic methods (i.e. multifactor dimensionality reduction analysis) are needed to assess the role of SHBG genotype in concert with other genetic and environmental risk factors [24].

\section{Acknowledgements}

Authors thank Dr Deniz Agirbasli, MD, PhD for her help in the interpretation of the data.

\section{Authors' contributions}

Dr Sunbul and Dr Agirbasli were the primary investigators of the study and were responsible for concept/design, data analysis/interpretation, and drafting the article. Dr Eren and Dr Nacar helped in genetic analysis/interpretation of the genetic data. Dr Agirbasli critically revised and approved the article.

Conflicts of interest: none declared

\section{References}

1. Expert Panel on Detection, Evaluation and Treatment of High Blood Cholesterol in Adults. Executive Summary of the Third Report of the National Cholesterol Education Program (NCEP) Expert Panel on Detection, Evaluation, and Treatment of High Blood Cholesterol in Adults (Adult Treatment Panel III). JAMA, 2001; 285: 2486-2497.

2. Balkau B, Charles MA. Comment on the provisional report from the WHO consultation. European Group for the Study of Insulin Resistance (EGIR). Diabet Med, 1999; 16: 442-443.

3. Alberti KG, Zimmet P, Shaw J; IDF Epidemiology Task Force Consensus Group. The metabolic syndrome: A new worldwide definition. Lancet, 2005; 366: 1059-1062.

4. Onat A, Hergenç G, Karabulut A, Albayrak S, Can G, Kaya Z. Serum sex hormone-binding globulin, a determinant of cardiometabolic disorders independent of abdominal obesity and insulin resistance in elderly men and women. Metabolism, 2007; 56: 1356-1362.

5. Onat A, Can G, Ciçek G, Ayhan E, Dogan Y. Predictive value of serum apolipoprotein B/LDL-cholesterol ratio in cardiometabolic risk: Population-based cohort study. Clin Biochem, 2010; 43: 1381-1386.

6. Ding EL, Song Y, Manson JE et al. Sex hormone-binding globulin and risk of type 2 diabetes in women and men. N Engl J Med, 2009; 361: 1152-1163.

7. Berndt SI, Chatterjee N, Huang WY et al. Variant in sex hormone-binding globulin gene and the risk of prostate cancer. Cancer Epidemiol Biomarkers Prev, 2007; 16: 165-18.

8. Key T, Appleby P, Barnes I, Reeves G; Endogenous Hormones and Breast Cancer Collaborative Group. Endogenous sex hormones and breast cancer in postmenopausal women: reanalysis of nine prospective studies. J Natl Cancer Inst, 2002; 94: 606-616.

9. Haiman CA, Riley SE, Freedman ML, Setiawan VW, Conti DV, Le Marchand L. Common genetic variation in the sex steroid hormone-binding globulin (SHBG) gene and circulating SHBG levels among postmenopausal women: The Multiethnic Cohort. J Clin Endocrinol Metab, 2005; 90: 2198-2204.

10. Dunning AM, Dowsett M, Healey CS et al. Polymorphisms associated with circulating sex hormone levels in postmenopausal women. J Natl Ca ncer Inst, 2004; 96: 936-945.

11. Eriksson AL, Lorentzon M, Mellström D et al. SHBG gene promoter polymorphisms in men are associated with serum sex hormone-binding globulin, androgen and androgen metabolite levels, and hip bone mineral density. J Clin Endocrinol Metab, 2006; 91: 5029-5037.

12. Onat A, Hergenc G, Keles I, Dogan Y, Türkmen S, Sansoy V. Sex difference in development of diabetes and cardiovascular disease on the way from obesity and metabolic syndrome. Metabolism, 2005; 54: 800-888.

13. National Cholesterol Education Program (NCEP) Expert Panel on Detection, Evaluation, and Treatment of High Blood Cholesterol in Adults (Adult Treatment Panel III). Third Report of the National Cholesterol Education Program (NCEP) Expert Panel on Detection, Evaluation, and Treatment of High Blood Cholesterol in Adults. (Adult Treatment Panel III) final report. Circulation, 2002; 106: 3143-3421. 
14. Onat A, Uysal O, Hergenc G. Assessment of the cohort of the Turkish Risk Factor Study with the Framingham risk function: An additional indicator of the high absolute coronary risk among Turks. Arch Turk Soc Cardiol, 2001; 29: 208-214.

15. Sowers M, Derby C, Jannausch ML, Torrens JI, Pasternk R. Insulin resistance, hemostatic factors, and hormone interactions in pre- and perimenopausal women: SWAN. J Clin Endocrinol Metab, 2003; 88: 4904-4910.

16. Karim R, Hodis HN, Stanczyk FZ, Lobo RA, Mack WJ. Relationship between serum levels of sex hormones and progression of subclinical atherosclerosis in postmenopausal women. J Clin Endocrinol Metab, 2008; 93: 131-138.

17. Ouyang P, Vaidya D, Dobs A et al. Sex Hormones Levels and Subclinical Atherosclerosis in Postmenopausal Women: The Multi-Ethnic Study of Atherosclerosis. Atherosclerosis, 2009; 204: 255-261.

18. Reddy KJ, Singh M, Bangit JR, Batsell RR. The role of insulin resistance in the pathogenesis of atherosclerotic cardiovascular disease: An updated review. J Cardiovasc Med, 2010; 11: 633-647.

19. Jaquish CE, Blangero J, Haffner SM, Stern MP, MacCluer JW. Quantitative genetics of serum sex hormone-binding globulin levels in participants in the San Antonio Family Heart Study. Metabolism, 1997; 46: 988-991.

20. Ring HZ, Lessov CN, Reed $\mathrm{T}$ et al. Heritability of plasma sex hormones and hormone binding globulin in adult male twins. J Clin Endocrinol Metab, 2005; 90: 3653-3658.

21. An P, Rice T, Gagnon J et al. A genetic study of sex hormone-binding globulin measured before and after a 20 -week endurance exercise training program: The HERITAGE Family Study. Metabolism, 2000; 49: 1014-1020.

22. Meikle AW, Stephenson RA, Lewis CM, Wiebke GA, Middleton RG. Age, genetic, and nongenetic factors influencing variation in serum sex steroids and zonal volumes of the prostate and benign prostatic hyperplasia in twins. Prostate, 1997; 33: 105-111.

23. Riancho JA, Valero C, Zarrabeitia MT, García-Unzueta MT, Amado JA, González-Macías J. Genetic polymorphisms are associated with serum levels of sex hormone binding globulin in postmenopausal women. BMC Med Genet, 2008; 9: 112.

24. Agirbasli M, Guney AI, Ozturhan HS et al. Multifactor dimensionality reduction analysis of MTHFR, PAI-1, ACE, PON1, and eNOS gene polymorphisms in patients with early onset coronary artery disease. Eur J Cardiovasc Prev Rehabil, 2011; 18: 803-809. 